It has been decided that the duplex design for the Isaac Newton telescope be abandoned and that attention be concentrated on the construction of a conventional paraboloid telescope. A committee is working out a detailed design on this basis, and substantial progress is reported.

\section{ONTARIO RESEARCH FOUNDATION REPORT FOR 1955}

T HE annual report of the Director of Research of the Ontario Research Foundation for 1955* refers to additions to the duties and responsibilities of the Foundation in consequence of the termination of the Research Council of Ontario. The Foundation is now authorized to spend 50,000 dollars a year on scholarships and fellowships for postgraduate students in science, and for the year 1955-56 forty-one scholarships were awarded. The estimates also provide for grants of 145,000 dollars to universities and colleges in Ontario for postgraduate research in the natural sciences and engineering, and sixty-four such grants were made for 1955-56. The advisory committees for research in fisheries and wild-life and in forestry and forest products and for industrial research have been reconstituted, and their membership is given in an appendix. The Director again notes the growing difficulty in recruiting an adequate number of Canadian graduates with the requisite scientific background and character and also the need for further space and equipment, particularly for pilot-plant operatives in the Metallurgy and Chemistry Departments in view of the growth of the Foundation's activities over the past ten years, during which its income has increased from 364,385 dollars in 1945 to $1,014,086$ dollars in 1955.

The Biochemistry Department has achieved further success in modifying chemically a lignin sulphonic acid phenol condensate and applying it in tanning heavy leather, and it is hoped that the Department will be able to re-examine potential sources of vegetable tannins in Canada. Workers under the Rice Mills Fellowship have met with continued success in the production of humidifier plates from rice hull ash, and they are now engaged in a study of experimental lots of acoustic tile. Besides cooperative work with other Departments, the infra-red laboratory has been used by eight companies in their own investigations. A close correlation has been noted in the oils and fats laboratory between the tendency of an oil to deteriorate and its ability to react with 2-thiobarbituric acid, and fodder yeast has been produced from cheese whey by a simple process.

The Department of Chemistry, using improved methods of paper chromatography, has determined quantitatively the nine lower members of the phosphoric acid series and occasionally up to the twelfth member, and has continued its work on phosphate glasses. It is proposed to concentrate the work of the air pollution laboratory on careful analysis of the atmosphere in relation to climatic conditions, and on a determination of the organic constituents and the ozone concentration. A commercial model has been constructed which is able to check accurately sixty piezo-electric quartz crystal units per hour.

* Ontario Research Foundation. Annual Report, 1955. Pp. 35. * Ontario Research Foundation, Annual Report
(Toronto: Ontario Research Foundation, 1956.)
A study of the viscosities of grafted copolymer solutions showed that the viscosity increases rapidly as the shear-rate decreases for branched copolymers but is unaffected for linear copolymers. The electroplating laboratory has found that large inclusions in commercial steel could be an important source of failure for nickel deposits of the order of $0.0001 \mathrm{in}$. thickness from a low-pH Watts bath. Work on the utilization of waste sulphite liquor continued.

The volume of work in the Engineering Section of the Department of Engineering and Metallurgy is two and a half times that in 1954. Pilot-plant work in the research on controlled-density steel has yielded important results on the economics of the process, furnace design and the production of the reducing gas; work in the ferious metallurgy laboratory included the chemical production of pure magnetite, the decrepitation of ores at various temperatures to improve concentrates, the design and construction of improved magnetic separators, particularly for handling extremely fine particles, and the design and construction of a machine for pelletizing iron ore concentrates. Fundamental work in the physics of metals is aimed at acquiring new knowledge about the fatigue process and applying this knowledge to discover new materials of high fatigue strength, as well as developing tests to measure fatigue damage. In the X-ray laboratory a helium bath has been obtained and the range of the X-ray spectrographic analysis has been extended to elements of lower atomic numbers.

In the Department of Parasitology, work continued on the blood protozoa in birds; and tests on the antimalarial drugs 'Daraprim', 'Camoquin' and 'Aralen' against $L$. simondi in ducks showed that 'Daraprim' prevented parasitæmia, but neither of the others had any prophylactic or therapeutic value. The investigation of the life-history of two species of flukes that occur in foxes and other carnivores was completed; 30 per cent of almost a thousand nests of forty-five species of birds examined were infested with thirteen different species of Proto. calliphora. In the Department of Physiography laboratory work was completed on minerals in the colloidal fraction of glacial tills and water-laid clays in southern Ontario, and a study was made of climate for peaches in Ontario. The Textile Department is concentrating its resources on short-term work in the immediate future, and undertaking only one or two fundamental problems, including the physical properties of viscose yarn and the resistance of nylon to immersion in water and exposure to light.

\section{RESEARCH ON ANIMAL PRODUCTION}

$T$ HE British Society of Animal Production was established towards the end of the Second World War for the purpose of bringing together those interested in both the science and practice of the breeding, feeding and management of farm animals, and the recently published volume of its Proceedings for $1955^{*}$ contains many interesting and important papers on current research in animal production. The following examples indicate the wide range of

* Proceedings of the British Society of Animal Production, 1955. Pp. 122. Edited by I. L. Mason and G. Wiener. (Edinburgh and London: Oliver and Boyd, Ltd., 1956.) $15 s$. 